\title{
Giant cell tumor of patella
}

\author{
Paudel S, Kayastha P, Pokhrel P, Shah A, Ghimire RK, Ansari MA
}

Department of Radiology and Imaging, Tribhuvan University Teaching Hospital, Maharajgunj Kathmandu

Correspondence address: Dr. Sharma Paudel, Department of Radiology and Imaging, Institute of Medicine, Tribhuvan University Teaching Hospital, Kathmandu, Nepal

E-mail: sharmapaudel@hotmail.com,drsharmapaudel@yahoo.com.

\begin{abstract}
Giant cell tumor of bone also known as osteoclastoma is a distinct clinical, roentgenographic and pathologic entity with specific characteristics. It is a benign but locally aggressive neoplasm of the epiphyseal or metaphyseal-epiphyseal region of long tubular bones extending to the articular surface. It usually occurs after skeletal maturation and is one of the rare bone tumors that more frequently affects women. We report here a case of giant cell tumor originating from the right patella diagnosed on fine needle aspiration cytology.
\end{abstract}

\section{Introduction}

Giant cell tumor (GCT) is a tumor found most often in the ends of long bones and is essentially located in the epiphyseal or metaphyseal or epiphyseal equivalent portions of bone. It is a locally aggressive neoplasm, generally arising in adults between the ages of 20 and 40 years, clinically possessing metastatic potential. It can also involve pelvic bones, vertebral bodies and small bones of digits.

The patella is a rare site with a reported incidence of less than one percent. Rare multicentric forms have been reported ${ }^{1-3}$. In this article, we report a case of GCT originating from the right patella which was diagnosed on fine needle aspiration cytology (FNAC).

\section{Case Report}

A 22-year-old female from Sindhupalchowk presented with a one and half year history of a progressively growing mass in the right patella associated with slight pain. It measured $7 \times 7 \mathrm{~cm}$ in its largest dimensions. The overlying skin was normal. She had no pulmonary symptoms. All hematological and biochemical investigations were within normal limits.

Patient underwent plain X-ray right knee AP and lateral views. Radiographs reveal expensile lytic lesion in right patella with marked thinning of cortex in anteroinferior aspect with few sclerotic septa within [FIG: 1].

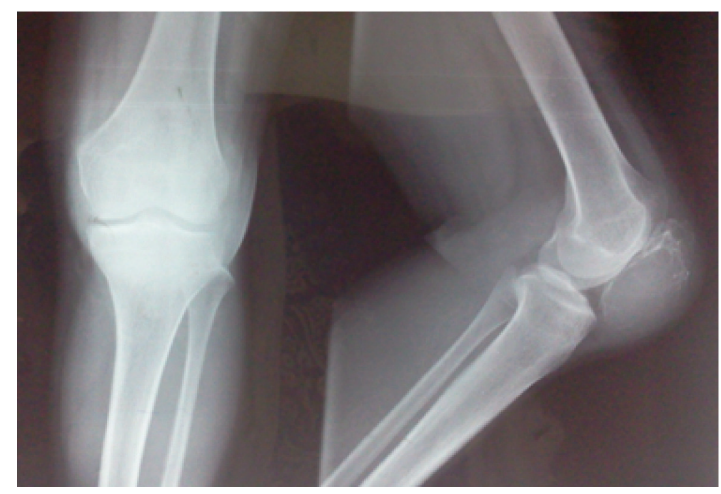

Fig 1: Antero-posterior and lateral radiograph showing expensile lytic lesion in patella

Patient underwent MRI of right knee. T2 weighted images were obtained in coronal and sagittal planes. Fat suppressed (STIR) images were obtained in sagittal plane [FIG: $2 \& 3$ ].

MRI shows approximately $7 \times 5 \times 5 \mathrm{~cm}$ heterogeneous lobulated expensile soft tissue mass in right patella 
extending up to the articular surface. Mass is surrounded by hypointense rim on $\mathrm{T} 2 \mathrm{~W}$ image except in inferomedial aspect. No evidence of extension into the joint space.
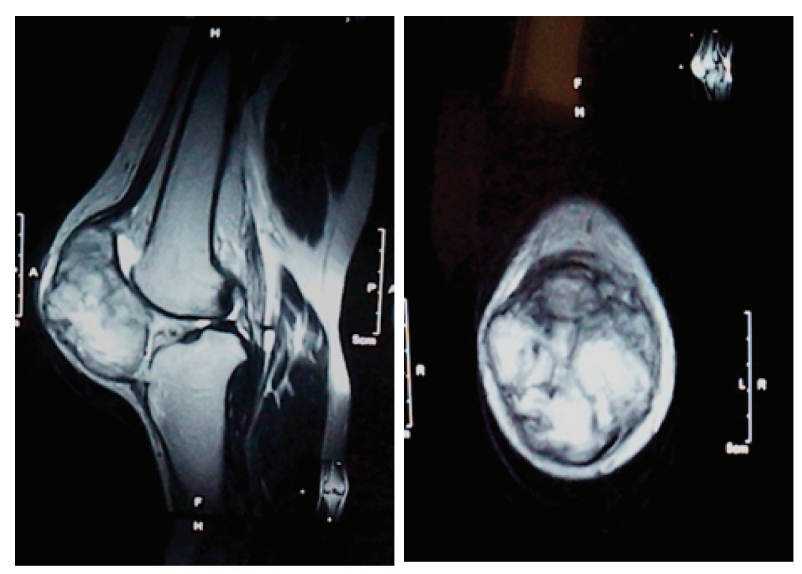

Fig. 2: T2 weighted Sagittal and Coronal images showing heterogeneously hyperintense mass in patella with hypointense rim

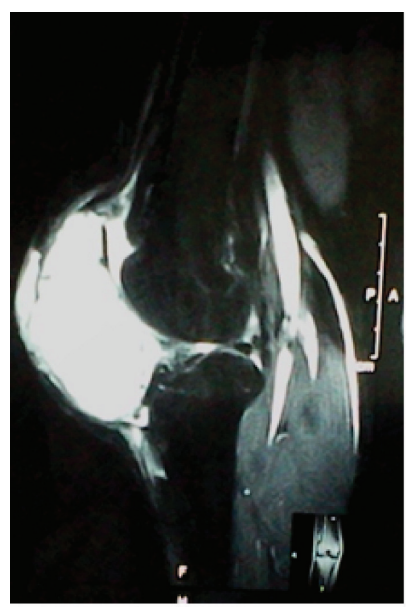

Fig. 3: Fat suppressed (STIR) sagittal image showing hyperintense mass in patella

Patient underwent fine needle aspiration cytology. Cytological smears were cellular and comprising aggregates of uniform appearing spindled stromal cells and innumerable osteoclast type giant cells, having variable number of nuclei. The nuclei of the stromal cells resembled those observed in the osteoclast type giant cells. The stromal cells showed high nuclear to cytoplasmic ratio with evenly distributed chromatin and inconspicuous to small nucleoli. No significant nuclear atypia was observed either in the giant cells or the background stromal cells. Mitotic figures were noted frequently.

\section{Discussion}

GCT of bone is an uncommon neoplasm accounting for about $4-5 \%$ of all primary bone tumors. The origin remains unknown. The giant cells may be derived from fused stromal cells of mononuclear phagocytic lineage. In fact, they may represent stromal precursor cells that have lost some of the detectable macrophage associated antigens or mononuclear phagocyte antigens seen in the more mature cells. GCT are generally considered benign but malignant cells can arise de novo or via transformation from a benign neoplastic giant cell lesion ${ }^{1-3}$.

The metaphyseal or epiphyseal zones of long bones are the most common sites, with $60 \%$ arising around the knee joint. Isolated cases have been reported in the scapula, sternum, patella, vertebra, skull and talus. ${ }^{1,3-5}$

Pain and an increase in local volume are the principal forms of presentation. Some patients present with pathological fracture resulting from weakening of the cortical bone. On a routine radiograph, GCT presents as an initially eccentric expanded lytic lesion, without a surrounding sclerotic halo, representing the cortical bone. As the lesion grows, it can encompass the entire circumference of the bone, causing rupture of the cortical bone, but a periosteal reaction is rarely seen ${ }^{1,2,5,6}$

Roentgenographic classification schemes have been used to characterize the tumor in any given case and attempt to predict the clinical outcome. Grading and staging of GCT have focused on (i). Histological features: Benign, aggressive and malignant, the latter having clearly pleomorphic features with abundant mitotic figures and (ii). Surgical staging: Clinically latent, active and aggressive. ${ }^{3}$ In the present case, although there were no overt anaplastic features in the tumor cells, mitotic activity were frequently detectable.

Giant cells are ubiquitous in bone lesions. A wide array of lesions may histologically mimic, depending on the quality and size of the biopsy. While examining lesions rich in these cells, if particular attention is paid to the background stromal cells and the clinico radiological data are correlated, then establishing the diagnosis becomes easier.

A differential diagnosis of aneurysmal bone cyst (ABC), brown tumor, chondroblastoma, chondromyxoid fibroma (CMF), non-ossifying fibroma (NOF), giant cell rich osteosarcoma and malignant fibrous histiocytoma can be considered on cytology. 
In general, all GCT's should be considered potentially aggressive and wide excision is recommended. ${ }^{2,3}$ Fine needle aspiration cytology has been useful in diagnosing similar lesions at rare sites like distal fibula. ${ }^{7}$ A primary malignant GCT of sacrum could be identified in a middle aged female ${ }^{8}$ as also a multifocal GCT in a skeletally immature patient. ${ }^{9}$

To conclude, our case illustrates the fact that giant cell tumors of patella can be mistaken for $\mathrm{ABC}$ and other malignant tumors of bone and soft tissues. The fine needle or image-guided biopsy would be diagnostic if adequate specimen is obtained.

\section{References}

1. Shin JS, Lee IS, Kim A, Kim BH. Giant cell tumour originating from the anterior arc of the rib. $\mathrm{J}$ Korean Med Sci. 2002;17:849-51. [PMC free article] [PubMed]

2. Kilpatrick SE, Renner JB, Creager A, editors. Diagnostic musculoskeletal surgical pathology: Clinicoradiologic and cytologic correlations. Pennsylvania: Saunders; 2004; 163-79.

3. Vigorita VJ, Ghehman B, Mintz D, editors. Orthopaedic pathology. 2nd ed. Philadelphia: Lippincott Williams and Wilkins; 2008; 280-9.

4. Mardi K, Sharma J. Primary giant cell tumour of soft parts - report of a case with fine needle aspiration cytology and histology findings. J Cytol. 2007; 24:58-9.

5. Cordeiro SZ, Cordeiro PDe B, Sousa AM, Lannes DC, Pierro GS. Giant cell tumour of the rib occupying the entire hemithorax. J Bras Pneumol. 2008; 34:185-8. [PubMed]

6. Hanna RM, Kyriakos M, Quinn SF. Case report 757: Giant cell tumour of rib. Skeletal Radiol. 1992; 21:482-8. [PubMed]

7. Dogra AS, Kulkarni SS, Bhosale PB. Distal fibular giant cell tumour. J Postgrad Med. 1995; 41:83-4. [PubMed]

8. Mahajan R, Sharma U, Talib VH. Primary malignant giant cell tumour of sacrum-a case report. Indian $\mathrm{J}$ Pathol Microbiol. 2001; 44:173-5. [PubMed]

9. Mondal A, Kundu B, Kundu R, Bhattacharya MK. Multifocal giant cell tumour of bone in a skeletally immature patient-a case report. Indian $\mathrm{J}$ Pathol Microbiol. 2001; 44:479-81. [PubMed] 